\title{
The effect of clary sage oil on staphylococci responsible for wound infections
}

\author{
Monika Sienkiewicz' Anna Głowacka², Katarzyna Poznańska-Kurowska², Andrzej Kaszuba², Anna Urbaniak ${ }^{3}$, \\ Edward Kowalczyk ${ }^{3}$
}

'Environmental Biology Department, Basic Sciences Institute, Medical University of Lodz, Lodz, Poland Head of Department: Anna Głowacka Prof. MUL

${ }^{2}$ Department of Dermatology, Pediatric Dermatology and Oncology, Medical University of Lodz, Lodz, Poland Head of Department: Prof. Andrzej Kaszuba MD, PhD

${ }^{3}$ Pharmacology and Toxicology Department, Medical University of Lodz, Lodz, Poland

Head of Department: Edward Kowalczyk Prof. MUL

Postep Derm Alergol 2015; XXXII, 1: 21-26

DOI: 10.5114/pdia.2014.40957

\begin{abstract}
Introduction: The spreading of bacterial antibiotic resistance among clinical strains of pathogenic bacteria has made investigators to search for other active antibacterial agents which could provide a valuable complement to the existing therapies.

Aim: To determine the antibacterial activity of clary sage oil (Salvia sclarea L.) against Staphylococcus clinical strains which were isolated from patients with wound infections.

Material and methods: A comprehensive evaluation of Staphylococcus clinical strain resistance to antibiotics was performed. The constituents of clary sage oil were assayed by GC-FID-MS analysis. The minimal inhibitory concentration (MIC) of the tested essential oil against staphylococci by the micro-dilution broth method was determined. Results: The clary sage oil was active against Staphylococcus aureus, S. epidermidis and S. xylosus with MIC values ranging from 3.75 to $7.00 \mu \mathrm{l} / \mathrm{ml}$.

Conclusions: The results of the in vitro tests encourage to use formulations containing sage oil as the active natural antimicrobial agent. Because of its antimicrobial properties clary sage oil may be applied to treat wounds and skin infections.
\end{abstract}

Key words: clary sage oil, minimal inhibitory concentration, Staphylococcus, wounds.

\section{Introduction}

The genus of Staphylococcus is a major Gram-positive coccus responsible for severe infections including dermatological ones. The major nosocomial pathogen is methicillin-resistant Staphylococcus aureus (MRSA) [1, 2], however coagulase-negative species (CoNS), including S. epidermidis and S. xylosus, are responsible for difficult to treat infectious diseases. The spread of multidrug resistant bacterial strains in patients, medical staff and hospital environment is largely caused by widespread use of antibiotic therapy [3, 4]. Many classes of antibiotics used before have become therapeutically useless. The risk of local and systemic infections development is high in hospital wards, especially in the elderly, immunosuppressed patients and those debilitated by chronic diseases [5-7].

Literature data report that essential oils are used to treat the respiratory tract, digestive system, skin infections and also may be applied in anticancer therapy and cardiovascular and nervous system disorders to reduce the level of cholesterol, as well as to decrease and regulate the glucose level. Various essential oils are components of the cosmetic cleaning products and food preservatives [8-11].

One of the most important essential oils which has been successfully used in medicine and cosmetology is tea tree oil [12]. The study by Hammer et al. [13] showed the susceptibility of transient and commensal skin flora

Address for correspondence: Monika Sienkiewicz PhD, Environmental Biology Department, Medical University of Lodz, 7/9 Żeligowskiego St, 90-752 Lodz, Poland, phone/fax: +48 4263932 03, e-mail: monika.sienkiewicz@umed.lodz.pl Received: 2.11.2013, accepted: 27.11.2013. 
to the essential oil of Melaleuca alternifolia. Their results suggest that tea tree oil may be useful in removing transient skin flora but maintains resident flora. Due to strong antifungal properties of essential oils they can be used in mixed skin infections. According to Adam et al. [14], the essential oils of Origanum vulgare subsp. hirtum, Mentha spicata, Lavandula angustifolia, and Salvia fruticosa exhibited antifungal properties against the human pathogens of Malassezia furfur, Trichophyton rubrum, and Trichosporon beigelii. The analyzed essential oils were tested with the Ames test and did not exhibit any mutagenic activity. The genus of Salvia is represented by over 900 species. One of the most important medicinal plants is Salvia officinalis. It has been used in treatment of tuberculosis, dysentery, coughing, indigestion, ulcer, psoriasis, as well as in skin and hair care [15]. The antimicrobial activity of plant extracts and essential oils from some species of Salvia is well documented in the research $[16,17]$. Clary sage extracts and essential oil possess antioxidant and antimicrobial properties [18, 19]. Dźamić et al. [20] showed fungicidal activity of the sage oil against Aspergillus, Penicillium, Fusarium, Trichoderma, Mucor, Candida and also its fungistatic and fungicidal activity against Cladosporium, Trichophyton, Alternaria and Phoma in very low levels. Hristova et al. [21] presented interesting results connected with high activity of the clary sage oil against many clinical strains of Candida species.

\section{Aim}

The present study on Staphylococcus isolates obtained from difficult-to-heal wound infections provided the information regarding strain sensitivity to the clary sage oil.

\section{Material and methods \\ Origin and identification of bacterial strains}

The tested Staphylococcus clinical strains were isolated from the swabs of patients with recurrent, difficult-to-treat wound infections treated at the Department of Dermatology, Pediatric Dermatology and Oncology, Medical University of Lodz, Poland, in 2012. The study included 61 patients; 41 males and 20 females (mean age of 56-63 years) with non-healing wounds arising in the course of diabetes, cardiovascular disorders, burns and surgery. Before admission, these patients were subjected unsuccessfully several times to outpatient treatment. The clinical material was collected before the antibiotic therapy. Staphylococci isolated from wounds were identified according to standard methods of culturing on Columbia Agar (bioMerieux), on Mannitol Salt Agar (bioMerieux), and determining the ability of bacteria to produce catalase and coagulase (bioMerieux). Microorganism species were identified by using API Staph tests (bioMerieux). The bacteria were incubated in $37^{\circ} \mathrm{C}$ for
24 h. Staphylococcus aureus ATCC 29213 strain was used as a control.

\section{Preparation and GC-FID-MS analysis of clary sage oil}

Salvia sclarea L. (Lamiaceae) oil was obtained from POLLENA-AROMA Poland. It was analyzed by GC-FID-MS in the Institute of General Food Chemistry, Lodz University of Technology, using a Trace GC Ultra apparatus (Thermo Electron Corporation) with FID and MS DSQ II detectors and FID-MS splitter (SGE). Operating conditions: apolar capillary column Rtx-1ms (Restek), $60 \mathrm{~m} \times$ $0.25 \mathrm{~mm}$ i.d., film thickness $0.25 \mu \mathrm{m}$; temperature program, $50-300^{\circ} \mathrm{C}$ at $4^{\circ} \mathrm{C} / \mathrm{min}$; SSL injector temperature $280^{\circ} \mathrm{C}$; FID temperature $300^{\circ} \mathrm{C}$; split ratio $1: 20$; carrier gas helium at a regular pressure $200 \mathrm{kPa}$; FID temperature $260^{\circ} \mathrm{C}$; carrier gas, helium; $0.5 \mathrm{ml} / \mathrm{min}$; split ratio $1: 20$. Mass spectra were acquired over the mass range 30-400 Da, ionization voltage $70 \mathrm{eV}$; ion source temperature $200^{\circ} \mathrm{C}$.

Identification of components was based on the comparison of their MS spectra with those in a laboratory-made MS library, commercial libraries (NIST 98.1, Wiley Registry of Mass Spectral Data, 8th Ed. and MassFinder 4) and with literature data $[22,23]$ along with the retention indices on an apolar column (Rtx-1, MassFinder 4) associated with a series of alkanes with linear interpolation $\left(\mathrm{C}_{8}-\mathrm{C}_{26}\right)$.

\section{Staphylococcus susceptibility to antibiotic testing}

Staphylococcus strains were cultivated on Columbia Agar medium and incubated at $37^{\circ} \mathrm{C}$ for $24 \mathrm{~h}$. Bacterial suspensions with an optical density of 0.5MF scale were prepared with the bioMerieux densitometer. Susceptibility testing was carried out with the use of disk-diffusion method on Mueller-Hinton II Agar and incubated at $37^{\circ} \mathrm{C}$ for $18 \mathrm{~h}$. The following antibiotics (Becton Dickinson) were used: Staphylococcus aureus, S. epidermidis and S. xylosus: FOX - cefoxitin (30 $\mathrm{\mu g}), \mathrm{P}$ - penicillin (10 IU), $\mathrm{E}$ - erythromycin $(15 \mu \mathrm{g}), \mathrm{DA}-$ clindamycin $(2 \mu \mathrm{g}), \mathrm{TE}$ - tetracycline $(30 \mu \mathrm{g}), \mathrm{TGC}$ - tigecycline $(15 \mu \mathrm{g}), \mathrm{C}-$ chloramphenicol (30 $\mu \mathrm{g}), \mathrm{CIP}$ - ciprofloxacin $(5 \mu \mathrm{g}), \mathrm{RA}$ - rifampin $(5 \mu \mathrm{g}), \mathrm{GM}$ - gentamicin $(10 \mu \mathrm{g})$, SXT - trimethoprim-sulfamethoxazole (1.25 $\mathrm{\mu g} / 23.75 \mu \mathrm{g})$, LZD - linezolid (30 $\mu \mathrm{g})$, FD - fusidic acid (10 $\mu \mathrm{g})$, QDA - quinupristin-dalfopristin (15 $\mathrm{gg}), \mathrm{VA}$ - vancomycin $(30 \mu \mathrm{g})$, and DPC - daptomycin (15 $\mu \mathrm{g})$.

The results were found according to the European Committee on Antimicrobial Susceptibility Testing (EUCAST) guidelines [24].

\section{Staphylococcus susceptibility to clary sage testing}

The clary sage antistaphylococcal activity was tested by the micro-dilution broth method. The essential oil was diluted in ethanol used as a stock solution. This stock solution was mixed with a $100 \mu$ l of Mueller-Hinton broth 
to obtain concentrations from $3.5 \mu \mathrm{l} / \mathrm{ml}$ to $7.25 \mu \mathrm{l} / \mathrm{ml}$. An inoculum containing $1-2 \times 10^{8}$ cells $/ \mathrm{ml}(10 \mu \mathrm{l})$ per well was added to broth with various oil concentrations, as well as to broth with no oil added (strain growth control) and were transferred to 96-well microtiter plates. The minimal inhibitory concentration (MIC) was determined after $24 \mathrm{~h}$ of incubation at $37^{\circ} \mathrm{C}$ under aerobic conditions [25]. Control media containing only alcohol (at concentrations used in the dilutions of clary sage) did not inhibit the growth of tested bacteria.

\section{Results}

\section{Constituents of Salvia sclarea oil}

Detailed analysis of the clary sage oil showed 56 constituents, out of which linalyl acetate (57.9\%) and linalo- ol (12.4\%) were determined as the main ones. Moreover, $\alpha$-pinene (4.5\%), $\alpha$-terpineol (3.5\%), sabinene (3.3\%), $\beta$-pinene (3.0\%), geranyl acetate (1.6\%), myrcene (1.5\%) and neryl acetate $(1.0 \%)$ were identified in large quantities (Table 1).

\section{The evaluation of Staphylococcus clinical strain} resistance

Three of Staphylococcus genera were isolated from patients with wound infections, including Staphylococcus aureus $(n=28)$, and coagulase-negative species: S. epidermidis $(n=19)$ and S. xylosus $(n=14)$. The number of resistant Staphylococcus strains to recommended antibiotics is presented in Figure 1.

The results of susceptibility testing show that the Staphylococcus strains isolated from wound infections

Table 1. Constituents of Salvia sclarea L. (clary sage) essential oil

\begin{tabular}{|c|c|c|c|c|c|c|c|}
\hline Number & Compound & $\%$ & RI & Number & Compound & $\%$ & RI \\
\hline 1 & $\alpha$-Thujene/Tricyclene & 0.3 & 923 & 29 & Ascaridole & 0.1 & 1221 \\
\hline 2 & $\alpha$-Pinene & 4.5 & 931 & 30 & Linalyl acetate & 57.9 & 1249 \\
\hline 3 & Camphene & $\operatorname{tr}$ & 941 & 31 & Safrole & 0.2 & 1268 \\
\hline 4 & Sabinene & 3.3 & 966 & 32 & $\alpha$-Terpinyl acetate & 0.1 & 1334 \\
\hline 5 & $\beta$-Pinene & 3.0 & 970 & 33 & Neryl acetate & 1.0 & 1344 \\
\hline 6 & Myrcene & 1.5 & 983 & 34 & $\alpha$-Cubebene & $\operatorname{tr}$ & 1349 \\
\hline 7 & $\alpha$-Phellandrene & 0.1 & 996 & 35 & Geranyl acetate & 1.6 & 1363 \\
\hline 8 & Car-3-ene & 0.2 & 1004 & 36 & $\alpha$-Copaene & $\operatorname{tr}$ & 1371 \\
\hline 9 & $\alpha$-Terpinene & 0.4 & 1009 & 37 & $\beta$-Bourbonene & 0.2 & 1377 \\
\hline 10 & p-Cymene & 0.5 & 1012 & 38 & $\beta$-Cubebene & 0.1 & 1385 \\
\hline 11 & 1,8-Cineole & 0.8 & 1020 & 39 & $\beta$-Elemene & 0.1 & 1389 \\
\hline 12 & Limonene & 0.9 & 1021 & 40 & $\beta$-Caryophyllene & 0.8 & 1420 \\
\hline 13 & (Z)- $\beta$-Ocimene & 0.1 & 1028 & 41 & $\beta$-Copaene & $\operatorname{tr}$ & 1428 \\
\hline 14 & (E)- $\beta$-Ocimene & 0.2 & 1038 & 42 & trans- $\alpha$-Bergamotene & $\operatorname{tr}$ & 1433 \\
\hline 15 & $\gamma$-Terpinene & 0.5 & 1049 & 43 & (E)- $\beta$-Farnesene & $\operatorname{tr}$ & 1447 \\
\hline 16 & trans-Sabinene hydrate & 0.1 & 1054 & 44 & $\alpha$-Humulene & 0.1 & 1452 \\
\hline 17 & trans-Linalool oxide (f) & $\operatorname{tr}$ & 1059 & 45 & Germacrene D & 0.5 & 1477 \\
\hline 18 & cis-Linalool oxide (f) & $\operatorname{tr}$ & 1073 & 46 & $\beta$-Selinene & $\operatorname{tr}$ & 1483 \\
\hline 19 & Terpinolene & 0.3 & 1079 & 47 & Myristicin & 1.6 & 1492 \\
\hline 20 & Linalool & 12.4 & 1090 & 48 & $\delta$-Cadinene & 0.1 & 1514 \\
\hline 21 & cis-Sabinene hydrate & $\operatorname{tr}$ & 1099 & 49 & Elemicin & $\operatorname{tr}$ & 1520 \\
\hline 22 & cis-p-Menth-2-en-1-ol & $\operatorname{tr}$ & 1108 & 50 & Spathulenol & $\operatorname{tr}$ & 1565 \\
\hline 23 & Borneol & $\operatorname{tr}$ & 1150 & 51 & Caryophyllene oxide & 0.1 & 1571 \\
\hline 24 & Terpinen-4-ol & 0.9 & 1163 & 52 & $\beta$-Eudesmol & $\operatorname{tr}$ & 1625 \\
\hline 25 & $\alpha$-Terpineol & 3.5 & 1175 & 53 & $\alpha$-Eudesmol & $\operatorname{tr}$ & 1637 \\
\hline 26 & $\gamma$-Terpineol & 0.2 & 1181 & 54 & Sclareoloxide & $\operatorname{tr}$ & 1881 \\
\hline 27 & Linalyl acetate & 0.1 & 1200 & 55 & Geranyllinalool & $\operatorname{tr}$ & 1906 \\
\hline 28 & Nerol & 0.6 & 1216 & 56 & Sclareol & 0.1 & 2206 \\
\hline
\end{tabular}

$\operatorname{tr}<0.05 \%$, \% - percentage of constituents, $R I-$ retention index. 


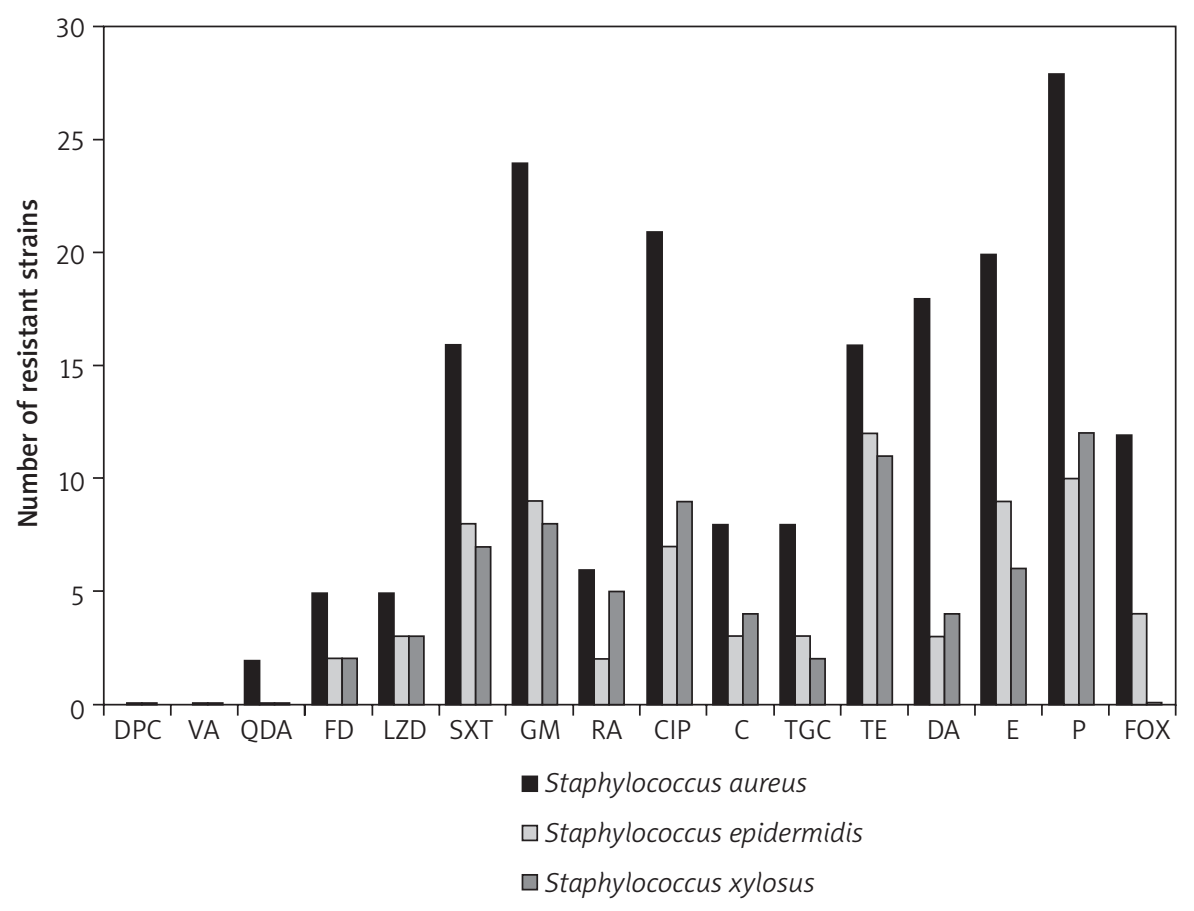

Figure 1. Staphylococcus clinical strains isolated from wounds resistant to recommended antibiotics

in the study were highly resistant to most of the $\beta$-lactam (penicillin), macrolide (erythromycin), lincosamides (clindamycin), tetracycline, fluoroquinolone (ciprofloxacin), aminoglycoside (gentamicin) antibiotics and sulfonamide (trimethoprim-sulfamethoxazole). Staphylococcus aureus clinical strains were much more resistant to recommended antibiotics than S. epidermidis and S. xylosus strains. There were 11 MRSA and 16 MSSA strains among the $S$. aureus isolates, but all of them were resistant to penicillin. The highest resistance of the coagulase-nega-

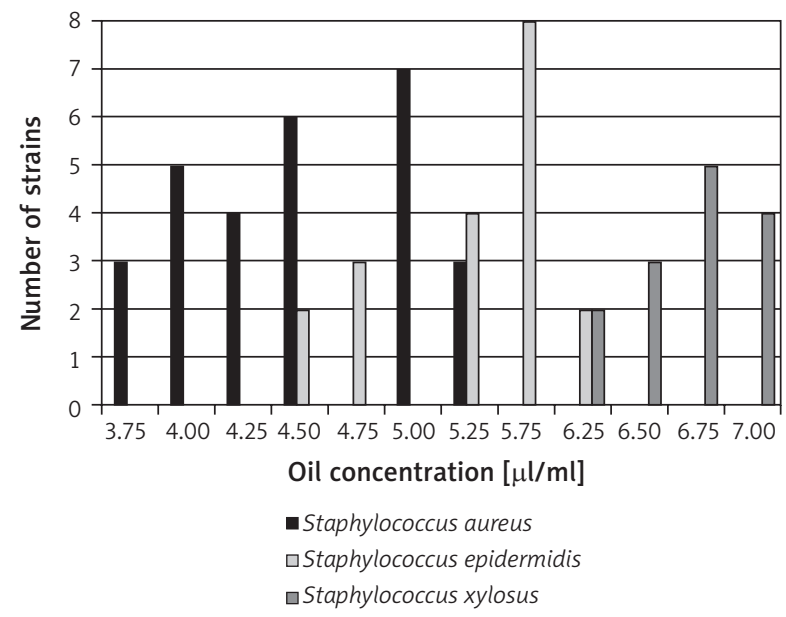

Figure 2. The activity of clary sage oil against Staphylococcus clinical strains isolated from wounds tive species was found for penicillin, erythromycin, tetracycline, ciprofloxacin, gentamicin and trimethoprim-sulfamethoxazole.

\section{The susceptibility of Staphylococcus clinical strains to clary sage oil}

The clary sage oil has the high antibacterial potential against all bacterial genera of Staphylococcus with MIC between 3.75-7.00 $\mu \mathrm{l} / \mathrm{ml}$. The approximate MIC values for $S$. aureus and S. epidermidis isolated from wounds were obtained. Staphylococcus aureus isolates including eleven MRSA and sixteen MSSA were inhibited by the clary sage oil at the concentrations of $3.75-5.25 \mu \mathrm{l} / \mathrm{ml}$. The concentrations from $4.50 \mu \mathrm{l} / \mathrm{ml}$ to $6.25 \mu \mathrm{l} / \mathrm{ml}$ inhibited the growth of $S$. epidermidis clinical strains. Strains of S. xylosus were the least sensitive to Salvia sclarea oil, with the MIC values ranging from $6.25 \mu \mathrm{l} / \mathrm{ml}$ to $7.00 \mu \mathrm{l} /$ $\mathrm{ml}$. The activity of clary sage oil against S. aureus, S. epidermidis and S. xylosus is presented in Figure 2.

\section{Discussion}

The study results show that the Salvia sclarea essential oil has the strong antistaphylococcal activity against clinical strains isolated from wound infections. Interestingly, the strains of species S. aureus and S. epidermidis were more susceptible to the clary sage oil, followed by strains of S. xylosus. Staphylococcus aureus strains including MRSA were simultaneously the most resistant 
to recommended antibiotics. Linalyl acetate (57.9\%) and linalool (12.4\%) were found to be the main compounds out of 56 constituents of the clary sage oil. It should be emphasized that the oil tested in the present study was consistent with requirements of the European Pharmacopoeia 6 [26] and the Polish Pharmacopoeia VIII [27] which specify precise amounts of linalyl acetate (56-78\%) and linalool (6.5-24\%). The clary sage oil contains linalyl acetate $(52.83 \%)$ and linalool (18.18\%) which have been studied by Dźamić et al. [20] and show the antifungal activity expressed as MIC in the range of $2.5 \mu \mathrm{l} / \mathrm{ml}$ to $25.0 \mu \mathrm{l} / \mathrm{ml}$. Our previous studies demonstrated that the lavender oil at the concentration from $1.5 \mu \mathrm{l} / \mathrm{ml}$ to $3.0 \mu \mathrm{l} / \mathrm{ml}$ inhibited the growth of resistant $S$. aureus strains isolated from wounds [28]. The composition of the analyzed lavender oil was similar to clary sage oil; linalyl acetate (33\%) and linalool (34.1\%) were the main constituents of oil from Lavandula angustifolia Mill. (Lamiaceae). The tested clary sage oil was active against all tested S. aureus clinical strains with MIC values ranging from $3.75 \mu \mathrm{l} / \mathrm{ml}$ to $5.25 \mathrm{\mu l} / \mathrm{ml}$. The strains of S. epidermidis and S. xylosus were susceptible to the clary sage oil at the concentration from $4.50 \mu \mathrm{l} / \mathrm{ml}$ to $7.00 \mu \mathrm{l} / \mathrm{ml}$. Peana et al. [29] have proven that linalool and linalyl acetate play a major role in the anti-inflammatory activity of essential oils. They recommended all plant species producing these monoterpene compounds as potential anti-inflammatory agents. In recent years, anti-microbial, anti-inflammatory and immune stimulating properties of essential oils have become a subject of interest to clinicians. This is largely due to serious problems in the therapeutic treatment of recurrent infections caused by resistant pathogens. Research shows that many of the oils can be used in the treatment of wounds and skin infections. Riella et al. [30] in their studies on animal models showed that essential oil from Lippia gracilis Schauer (Verbenaceae) with its major component - thymol is a promising compound to be used in treatment of inflammatory processes as well as wound healing. According to Tavares et al. [31], the essential oil from Distichoselinum tenuifolium (Lag.) Garcia Martin \& Silvestre revealed significant antifungal activity against Cryptococcus neoformans and dermatophyte strains and significantly inhibited nitric oxide production stimulated by LPS in macrophages, without affecting cell viability at concentrations ranging from $0.64 \mu \mathrm{l} / \mathrm{ml}$ to $1.25 \mu \mathrm{l} / \mathrm{ml}$. Yoon et al. [32] proved that essential oil from Abies koreana can be used in the treatment of acne because of their antibacterial potential against Propionibacterium acnes and S. epidermidis. The tested oil reduced the LPS-induced secretion of tumor necrosis factor- $\alpha$ (TNF- $\alpha$ ), interleukin-1 $\beta$ (IL-1 $\beta)$, IL-6, nitric oxide and prostaglandin E(2) in RAW 264.7 macrophages, indicating that it has anti-inflammatory effects. Süntar et al. [33] presented the interesting results connected with the use of a new ointment formulation to provide more efficient wound healing. This ointment containing essential oils from Hypericum perforatum L., Origanum majorana L., Origanum minutiflorum Schwrd. et Davis and Salvia triloba L. not only affected wound healing, but also exerted bactericidal and candicidal activities. Due to the enormous interest in staphylococci, including MRSA and coagulase-negative species that are increasingly being the cause of the difficult infections, the Staphylococcus genus was chosen for the investigations with clary sage oil. The studies of the clary sage oil activity against Gram-negative pathogens are also planned. The Escherichia, Enterobacter, Acinetobacter, Citrobacter, Pseudomonas and Proteus species which were isolated from recurrent, difficult-to-treat wound infections will be investigated. Our results may provide the basis for further research on the local use of the clary sage oil as a complement of existing anti-infective therapies in clinical conditions. Data on the antimicrobial activity of numerous plants have been scientifically confirmed inter alia against pathogenic microorganisms resistant to antimicrobials [34, 35].

\section{Acknowledgments}

The authors would like to thank Professor Danuta Kalemba from the Institute of General Food Chemistry, Lodz University of Technology, Poland, for clary sage oil analysis.

\section{Conflict of interest}

The authors declare no conflict of interest.

\section{References}

1. DeLeo FR, Otto M, Kreiswirth BN, Chambers HN. Community-associated methicillinresistant Staphylococcus aureus. Lancet 2010; 375: 1557-68.

2. Boers SA, van Ess I, Euser SM, et al. An outbreak of a multiresistant methicillin-susceptible Staphylococcus aureus (MR-MSSA) strain in a burn centre: the importance of routine molecular typing. Burns 2011; 37: 808-13.

3. Valencia IC, Kirsner RS, Kerdel FA. Microbiologic evaluation of skin wounds: alarming trend toward antibiotic resistance in an inpatient dermatology service during a 10-year period. J Am Acad Dermatol 2004; 50: 845-9.

4. Edwards R, Harding KG. Bacteria and wound healing. Curr Opin Infect Dis 2004; 17: 91-6.

5. Higaki S, Kitagawa T, Kagoura M, et al. Predominant Staphylococcus aureus isolated from various skin diseases. I Int Med Res 2000; 28: 187-90.

6. von Eiff C, Proctor RA, Peters G. Coagulase-negative staphylococci. Pathogens have major role in nosocomial infections. Prostgrad Med 2001; 110: 63-76.

7. Winston DJ, Dudnick DV, Chapin M, et al. Coagulase-negative staphylococcal bacteremia in patients receiving immunosuppressive therapy. Arch Intern Med 1983; 143: 32-6.

8. Edris AE. Pharmaceutical and therapeutic potentials of essential oils and their individual volatile constituents: a review. Phytother Res 2007; 21: 308-23. 
9. Burt S. Essential oils: their antibacterial properties and potential applications in foods - a review. Int J Food Microb 2004; 94: 223-53.

10. Kobayashi A, Okamoto H, Okada F. Antiseptic disinfectant, and cosmetics and toiletries, medicine or food containing the same. US20087384646, 2008.

11. Kobayashi A, Okamoto H, Okada F. Antiseptic bactericides and cosmetics, drugs and foods containing the antiseptic bactericides. US20107754774, 2010.

12. Heinrich M, Barnes J, Gibbons S, Williamson EM. Fundamentals of pharmacognosy and phytotherapy. Churchill Livingstone, Edinbrugh 2004; 245-52.

13. Hammer KA, Carson ChF, Riley TV. Susceptibility of transient and commensal skin flora to the essential oil of Melaleuca alternifolia (tea tree oil). Am J Infection Control 1996; 24: 186-9.

14. Adam K, Sivropoulou A, Kokkini S, et al. Antifungal activities of Origanum vulgare subsp. hirtum, Mentha spicata, Lavandula angustifolia, and Salvia fruticosa essential oils against human pathogenic fungi. J Agric Food Chem 1998; 46: 1739-45.

15. Izzo AA. Herb-drug interactions. An overview of the clinical evidence. Fundam Clin Farmacol 2005; 19: 1-16.

16. Barnes J, Anderson LA, Philipson DJ. Sage. Herbal medicines. 3rd ed. The Pharmaceutical Press, London 2007.

17. Delamare AP, Moschen-Pistorello IT, Artico L, et al. Antibacterial activity of the essential oils of Salvia officinalis $L$. and Salvia triloba L. cultivated in South Brazil. Food Chem 2007; 100: 603-8.

18. Gülçin I. Evaluation of the antioxidant and antimicrobial activities of clary sage (Salvia sclarea L.). Turk J Agric For 2004; 28: 25-33.

19. Pitarokili D, Couladis M, Petsikos-Panayotarou N, Tzakou O. Composition and antifungal activity on soil-borne pathogens of essential oil of Salvia sclarea from Greece. L Agric Food Chem 2002; 20: 6688-91.

20. Dźamić A, Sokovic M, Ristic M, et al. Chemical composition and antifungal activity of Salvia sclarea (Lamiaceae) essential oil. Arch Biol Sci 2008; 60: 233-7.

21. Hristova Y, Gochev V, Wanner J, et al. Chemical composition and antifungal activity of essential oil of Salvia sclarea L. from Bulgaria against clinical isolates of Candida species. J BioSci Biotech 2013; 2: 39-44.

22. Adams RP. Identification of essential oil components by gas chromatography/mass spectroscopy. 4th ed. Allured Publishing Corporation: Carol Stream, IL, USA, 2007.

23. Joulain D, König WA. The atlas of spectral data of sesquiterpene hydrocarbons. EB-Verlag, Hamburg 1998.

24. European Committee on Antimicrobial Susceptibility Testing (EUCAST). Breakpoint Tables for Interpretation of MICS and Zone Diameters, version 2.0; valid from 1 January 2012; Available online: www.eucast.org (accessed on 16 December 2012).

25. Kalemba D, Kunicka A. Antibacterial and antifungal properties of essential oils. Curr Med Chem 2003; 10: 813-29.

26. European Pharmacopoeia. 6th ed. Council of Europe, Strasbourg 2008.

27. Polish Pharmacopeia VIII. 8th ed. Polish Pharmaceutical Society, Warsaw 2008.

28. Sienkiewicz M, Łysakowska M, Ciećwierz J, et al. Antibacterial activity of thyme and lavender essential oils. Med Chem 2011; 7: 674-89.

29. Peana AT, D, Aquila PS, Panin F, et al. Anti-inflammatory activity of linalool and linalyl acetate constituents of essential oils. Phytomed 2002; 9: 721-6.
30. Riella KR, Marinho RR, Santos JS, et al. Anti-inflammatory and cicatrizing activities of thymol, a monoterpene of the essential oil from Lippia gracilis, in rodents. J Ethnopharmacol 2012; 143: 656-63.

31. Tavares AC, Gonçalves MJ, Cruz MT, et al. Essential oils from Distichoselinum tenuifolium: chemical composition, cytotoxicity, antifungal and anti-inflammatory properties. J Ethnopharmacol 2010; 130: 593-8.

32. Yoon WJ, Kim SS, Oh TH, et al. Abies koreana essential oil inhibits drug-resistant skin pathogen growth and LPS-induced inflammatory effects of murine macrophage. Lipids 2009; 44: 471-6.

33. Süntar I, Akkol EK, Keleş H, et al. A novel wound healing ointment: a formulation of Hypericum perforatum oil and sage and oregano essential oils based on traditional Turkish knowledge. J Ethnopharmacol 2011; 134: 89-96.

34. Silva N, Fernandes J. Biological properties of medicinal plants: a review of their antimicrobial activity. J Venom Anim Toxinsincl Trop Dis 2010; 16: 402-13.

35. Elbashiti TA, Elmanama AA, Masad AA. The antibacterial and synergistic effects of some Palestinian plants extract on Escherichia coli and Staphylococcus aureus. Funct Plant Sci Biotechnol 2011; 5: 57-62. 